Journal of Bangladesh Academy of Sciences, Vol. 37, No. 1, 73-82, 2013

\title{
DIELECTRIC AND TRANSPORT PROPERTIES OF Zn-SUBSTITUTED COBALT FERRITES
}

\author{
AMRITA KHAN, MAHABUB ALAM BHUIYAN*, GOLAM DASTEGIR \\ AL-QUADERI, KAZI HANIUM MARIA, SHAMIMA CHOUDHURY, \\ KAZI MD. AMJAD HOSSAIN ${ }^{1}$, SHIRIN AKTHER ${ }^{1}$ AND D. K. SAHA ${ }^{1}$ \\ Department of Physics, University of Dhaka, Dhaka-1000, Bangladesh
}

\begin{abstract}
Effect of $\mathrm{Zn}$ content on the dielectric and transport properties of $\mathrm{CoZn}_{\mathrm{x}} \mathrm{Fe}_{2-\mathrm{x}} \mathrm{O}_{4}(\mathrm{x}=0.0,0.1$, $0.2,0.3$ and 0.4 ), prepared by standard double sintering ceramic technique, sintered at $1000^{\circ} \mathrm{C}$ for 4 hours were investigated. The X-ray diffraction (XRD) pattern of the prepared samples showed single phase inverse-spinel structure without any detectable impurity. Lattice constant of the samples increased with the increasing $\mathrm{Zn}$ concentration which follows Vegard's law. The theoretical densities of these samples remained almost constant whereas the bulk density decreased with $\mathrm{Zn}$ content up to $\mathrm{x}=0.2$. But with further increase of $\mathrm{Zn}$ content the bulk density increased. The porosity of the prepared samples showed the opposite trend. The dielectric constant $\left(\epsilon^{\prime}\right)$ measurement showed the normal dielectric behavior of the prepared ferrite. The DC electrical resistivity of the prepared samples decrease with increasing temperature which indicates the semiconducting behavior of the prepared ferrites. The $\mathrm{Zn}$ concentration showed pronounced effect on the resistivity at room temperature. Possible explanation for the observed features of densities, porosity, dielectric constant and resistivity of the studied samples are discussed.
\end{abstract}

Key words: Dielectric, Transport properties, Zinc content, Cobalt ferrites

\section{INTRODUCTION}

The study of spinel ferrites is of great importance from both the fundamental and the applied research points of view. They have many applications in high frequency devices and play a useful role in technological and magnetic applications because of their high electrical resistivity and consequently for low losses over a wide range of frequency. Polycrystalline ferrites are supposed to be very good dielectric materials with low conductivity and have a wide field of technological applications in the range from microwave to radio wave frequencies. The electrical conduction and dielectric behavior of ferrites markedly depended on sample preparation conditions such as sintering temperature, chemical composition, the quantity and type of additives. Dispersion in dielectric constant with frequency in polycrystalline ferrites is strongly dependent on the

*Corresponding author: <mail2mahabub@gmail.com>.

${ }^{1}$ Materials Science Division, Atomic Energy Centre, Dhaka-1000, Bangladesh. 
polarization process (Ahmed and Bishay 2003, Maria et al. 2010) and is also related to the Verway conduction mechanism (Iwauchi 1971).

The $\mathrm{CoZn}_{\mathrm{x}} \mathrm{Fe}_{2-\mathrm{x}} \mathrm{O}_{4}$ is considered as one of the important magnetic oxides with spinel structure because of its high electrical resistivity, relatively high Curie temperature, low cost, high mechanical hardness and environmental stability. It has been found that if $\mathrm{Fe}$ ions are replaced by $\mathrm{Zn}$ ion, the electrical properties are modified. In this work, the dielectric and transport properties of $\mathrm{Zn}$ substituted cobalt ferrite has been studied.

\section{EXPERIMENTAL DETAILS}

Ferrite samples with chemical formula $\mathrm{CoZn}_{\mathrm{x}} \mathrm{Fe}_{2-\mathrm{x}} \mathrm{O}_{4}(\mathrm{x}=0.0,0.1,0.2,0.3,0.4)$ were prepared by the standard double sintering ceramic technique. Powders of $\mathrm{Co}_{3} \mathrm{O}_{4}(99.9 \%)$, $\mathrm{ZnO}(99.9 \%)$ and $\mathrm{Fe}_{2} \mathrm{O}_{3}(99.9 \%)$ were used as raw materials. Stoichiometric amounts of required powders were mixed thoroughly and then calcined at $800^{\circ} \mathrm{C}$ for 3 hours. The calcined powders were then pressed uniaxially into disk-shaped and toroid-shaped samples. The samples were then sintered at $1000^{\circ} \mathrm{C}$ for 4 hours. The surfaces of all the samples were polished in order to remove any oxide layer during the process of sintering.

The X-ray diffraction patterns have been observed by using the PHILIPS X'PERT PRO X-ray diffraction system. The two surfaces of each pellet shaped samples were coated with silver paste as contact material for electrical and dielectric measurements. Dielectric and electrical properties were carried out by using WAYNEKERR INDUCTANCE ANALYZER 3255B and electrometer Keithley model 6514. The experiments were done at Materials Science Division, Atomic Energy Centre, Dhaka.

\section{RESULTS AND DISCUSSION}

The structural study is essential for optimizing the properties needed for various applications. The phase identification and lattice parameters are determined by an X-ray diffractometer. The X-ray diffraction pattern of the prepared samples sintered at $1000^{\circ} \mathrm{C}$ for 4 hours are shown in Fig. 1. As can be seen from the XRD patterns, it is observed that the position of the peaks comply with the reported values (Nalla Somaiah et al. 2012). The observed peaks at (220), (311), (222), (440), (422), (511), and (400) indicate that the $\mathrm{CoZn} \mathrm{Fe}_{2-\mathrm{x}} \mathrm{O}_{4}$ material also crystallizes in the inverse spinel phase in a manner similar to that of $\mathrm{CoFe}_{2} \mathrm{O}_{4}$. The sharp peaks reveal that the samples are in good crystalline form. One peak between (222) and (440) has been observed which is due to the charge valence of the cobalt compounds $\left(\mathrm{Co}^{2+}\right.$ and $\mathrm{Co}^{3+}$ in $\left.\mathrm{Co}_{3} \mathrm{O}_{4}\right)$ which is not neutralized and a fraction of $\mathrm{Fe}$ atoms is coming out of the spinel lattices to form the additional phase (Bhowmik et al. 2010). 


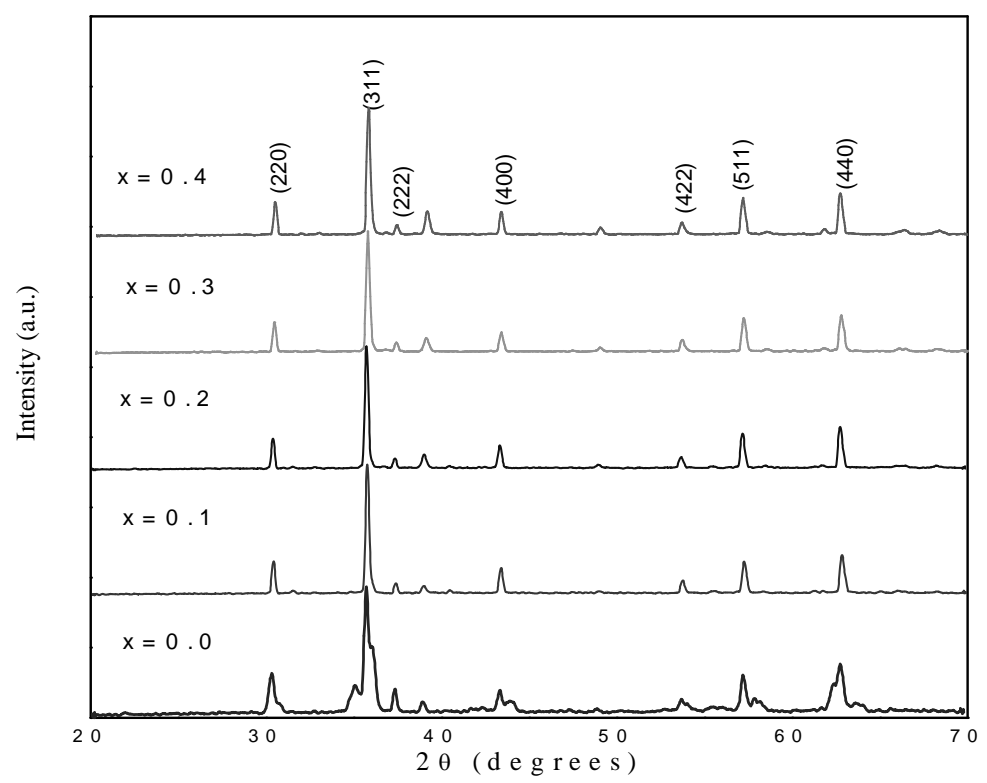

Fig. 1. X-ray diffraction pattern of $\mathrm{CoZn}_{\mathrm{x}} \mathrm{Fe}_{2-\mathrm{x}} \mathrm{O}_{4}$ ferrite samples for $\mathrm{x}=0.0,0.1$, $0.2,0.3$ and 0.4 sintered at $1000^{\circ} \mathrm{C}$.

Using standard XRD data and Nelson-Riley function (Nelson and Riley 1945)

$$
F(\theta)=\frac{1}{2}\left[\frac{\cos ^{2} \theta}{\sin \theta}+\frac{\cos \theta}{\theta}\right]
$$

lattice parameters (a) were determined. The "a" value ranges between $8.3000 \AA$ and $8.5000 \AA$ is typical of spinel ferrites. The lattice constant determined from XRD for pure $\mathrm{CoFe}_{2} \mathrm{O}_{4}$ is $8.3566 \AA$ which is smaller than the reported value $(8.387 \AA$ ) (Bharati and Ramana 2011). This difference may be due to the starting material of our sample. In general, divalent $\mathrm{Co}$ compound $(\mathrm{CoO})$ and trivalent $\mathrm{Fe}$ compound (e.g., $\alpha-\mathrm{Fe}_{2} \mathrm{O}_{3}$ (Hematite)) are used as the starting materials to form the single phase cobalt ferrite, which is different from authors' starting material. In principle, $\mathrm{Co}^{2+}$ ions will prefer to occupy the $\mathrm{B}$ sites by replacing $\mathrm{Fe}^{2+}$ ions in the $\mathrm{Fe}$ rich regime of cobalt ferrite (Kim et al. 2006). In this research, $\mathrm{Co}_{3} \mathrm{O}_{4}$ and $\mathrm{Fe}_{2} \mathrm{O}_{3}$ for the formation of cobalt ferrite have been used. In the presence of multi valence state of $\mathrm{Co}$ ions (i.e., $\mathrm{Co}^{2+}$ and $\mathrm{Co}^{3+}$ ), the lattice constant differs from the reported one. Substituting $\mathrm{Zn}$ for $\mathrm{Fe}$ increases the value of lattice constant for $\mathrm{CoZn}_{\mathrm{x}} \mathrm{Fe}_{2-\mathrm{x}} \mathrm{O}_{4}(\mathrm{x}=0.1,0.2,0.3,0.4)$ as compared to that for $\mathrm{CoFe}_{2} \mathrm{O}_{4}$. This behavior can be explained by the fact that the radius of $\mathrm{Zn}^{2+}(0.88 \AA$ ) (Singhal et al. 2010) ions in tetrahedral and octahedral sites is greater than that of $\mathrm{Fe}^{3+}(0.64 \AA)$ (Kumar and Kar 2012) ions, each of the site replacing $\mathrm{Fe}^{2+}$ with $\mathrm{Zn}^{2+}$ is expected to increase lattice constant (Dean 2005). In Fig. 2, lattice constants of all the samples were plotted 
against $\mathrm{Zn}$-content. From Fig. 2 it is observed that lattice constant increases with the increasing $\mathrm{Zn}^{2+}$ concentration which follows Vegard's law (Denton and Ashcroft 1991).

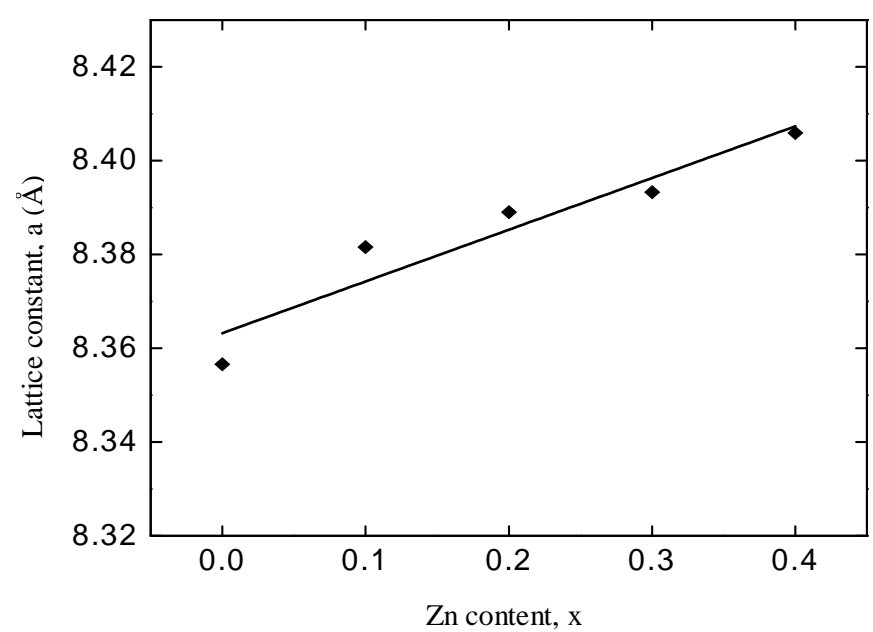

Fig. 2. Variation of lattice constant with $\mathrm{Zn}$ content.

The particle size of the samples has been calculated using Scherrer's formula,

$$
T=\frac{0.94 \lambda}{\beta \cos \theta_{B}}
$$

where, $\lambda$ is the wavelength of the incident X-ray beam, $\theta_{B}$ is the Bragg diffraction angle and $\beta$ is the angular line width of half maximum intensity. From the calculation, it is observed that particle size decreases for $\mathrm{x}=0.1$ and increases for $\mathrm{x}=0.3$ which may be due to the sintering temperature.

The theoretical density, $\rho_{t h}$, was calculated using the expression,

$$
\rho_{t h}=\frac{8 M}{N_{A} a_{o}^{3}}
$$

where, $N_{A}$ is the Avogedro's number, $M$ is the molecular weight and $a_{o}$ is the lattice constant. The porosity was calculated using the relation

$$
P=\left(\frac{\rho_{t h}-\rho_{B}}{\rho_{t h}}\right) \times 100
$$

The calculated lattice constant, particle size, density, porosity for different samples is given in Table 1. 
Table 1. Lattice constant, particle size, theoretical density, bulk density and porosity for the samples with the composition $\mathrm{CoZn}_{\mathrm{x}} \mathrm{Fe}_{2-\mathrm{x}} \mathrm{O}_{4}$.

\begin{tabular}{lllllc}
\hline $\begin{array}{l}\text { Zn } \\
\text { content, x }\end{array}$ & $\begin{array}{c}\text { Lattice } \\
\text { constant, } \mathrm{a}_{\mathrm{o}}(\AA)\end{array}$ & $\begin{array}{c}\text { Particle size, } \\
\mathrm{T}(\mathrm{nm})\end{array}$ & $\begin{array}{c}\text { Theoretical density, } \\
\rho_{\mathrm{x} \text {-ray }}(\mathrm{g} / \mathrm{c} . \mathrm{c} .)\end{array}$ & $\begin{array}{c}\text { Bulk density, } \\
\rho_{\mathrm{B}}(\mathrm{g} / \mathrm{c} . \mathrm{c} .)\end{array}$ & $\begin{array}{c}\text { Porosity, } \\
\mathrm{P}(\%)\end{array}$ \\
\hline 0.0 & 8.3566 & 73.8 & 5.3401 & 3.66 & 31.46 \\
0.1 & 8.3815 & 63.3 & 5.3142 & 3.59 & 32.39 \\
0.2 & 8.389 & 63.3 & 5.3214 & 3.45 & 35.15 \\
0.3 & 8.3933 & 68.1 & 5.3347 & 3.69 & 30.76 \\
0.4 & 8.4056 & 68.1 & 5.3326 & 3.65 & 31.52 \\
\hline
\end{tabular}

Density plays an important role in controlling the properties of polycrystalline ferrites. The effect of $\mathrm{Zn}$ on the theoretical density $\left(\rho_{\mathrm{th}}\right)$, bulk density $\left(\rho_{\mathrm{B}}\right)$ and porosity (P) are shown in the Table 1. From the table it is observed that the bulk density $\left(\rho_{B}\right)$ is lower than the theoretical density $\left(\rho_{\mathrm{th}}\right)$. This may be due to the existence of pores which were formed and developed during the sample preparation or the sintering process. From the table it is also observed that, the theoretical densities of these samples remain almost constant whereas the bulk density decreases with $\mathrm{Zn}$ content up to $\mathrm{x}=0.2$. This might be due to the limited content of $\mathrm{Zn}$ and many generated intergranular pores. Then the bulk density increases with $\mathrm{Zn}$ content for $\mathrm{x}=0.3$ and for further addition with $\mathrm{x}=0.4$ it decreases which might be caused by the existence of slight amount of metal oxides such as $\mathrm{M}^{2+} \mathrm{O}\left(\mathrm{M}^{2+}: \mathrm{Fe}, \mathrm{Zn}\right)$. Similar behavior was observed by (Xiwei et al. 2002).

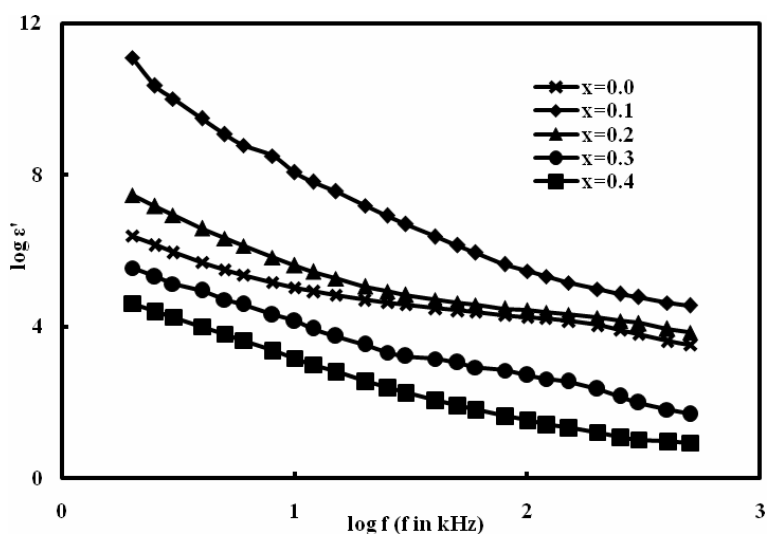

Fig. 3. Frequency dependent real part of dielectric constant.

The porosity of ceramic samples results from the two sources, intra-granular porosity and intergranular porosity (Sattar et al. 2005). The intra-granular porosity depends mainly on the grain size (Bellad et al. 2000). Thus the total porosity can be written as,

$$
\mathrm{P}=\mathrm{P}_{\text {intra }}+\mathrm{P}_{\text {inter }}
$$


It is observed that porosity behaves completely opposite as bulk density. Porosity of this material initially increases up to $\mathrm{x}=0.2$ then decreases for $\mathrm{x}=0.3$. And again it increases for $\mathrm{x}=0.4$. The composition $\mathrm{x}=0.3$ has the highest bulk density and lowest porosity.

Fig. 3. shows the variation of dielectric constant $\varepsilon^{\prime}$ with frequency at room temperature for different composition of $\mathrm{CoZn}_{\mathrm{x}} \mathrm{Fe}_{2-\mathrm{x}} \mathrm{O}_{4}$. It can be seen from Fig. 3 that the dielectric constant is found to decrease continuously with increasing frequency for all the specimens exhibiting normal dielectric behavior of ferrites. The dielectric dispersion is rapid at lower frequency region and remains almost independent at the high frequency region. The incorporation of $\mathrm{Zn}$ into the $\mathrm{CoZn}_{\mathrm{x}} \mathrm{Fe}_{2-\mathrm{x}} \mathrm{O}_{4}$ has no pronounced effect on the dielectric constant at high frequency, but significantly decreases the dielectric constant in the low frequency range. This type of behavior was observed in a number of ferrites such as Mg-Cu-Zn ferrites (Bammannavar et al. 2007 and Zhenxing et al. 2001), Li-Co ferrites (Gupta et al. 2007), Ni-Cu-Zn ferrites (Zhenxing et al. 2003), Li-Mg-Ti ferrites (Bellad and Chougule 2000) and Cu-Cd ferrites (Kolekar et al. 1995). The dielectric behavior of ferrites may be explained on the basis of the mechanism of the dielectric polarization process and is similar to that of the conduction process. The electronic exchange $\mathrm{Fe}^{2+} \leftrightarrow \mathrm{Fe}^{3+}$ gives the local displacement of electrons in the direction of the applied electric field, which induces the polarization in ferrites (Iwauchi 1971 and Kolekar et al. 1995). The magnitude of exchange depends on the concentration of $\mathrm{Fe}^{2+} /$ $\mathrm{Fe}^{3+}$ ion pairs present in the $\mathrm{B}$ site for the present ferrite. The sample $\mathrm{x}=0.1$ showed the maximum dispersion while that with $\mathrm{x}=0.0$ showed a least frequency dependence. The presence of $\mathrm{Fe}^{2+}$ ions in excess amount favours the polarization effects. Thus, the greater dispersion observed in the sample with $\mathrm{x}=0.1$ can be attributed to the presence of $\mathrm{Fe}^{2+}$ ions in excess amount which could be formed at elevated temperature. Similarly, the weak dependence of dielectric constant on frequency in the $x=0.0$ sample can be due to lack of $\mathrm{Fe}^{2+} / \mathrm{Fe}^{3+}$ ions concentration. The observed decrease in dielectric constant with increase in frequency is due to the fact that above certain frequencies the electronic exchange between $\mathrm{Fe}^{2+}$ and $\mathrm{Fe}^{3+}$ ions does not follow the frequency of the applied ac field. The samples have high values of $\varepsilon^{\prime}$ in the order of $10^{3}-10^{8}$ at low frequencies. This could be explained using Koop's phenomenological theory (Koops 1951), which was based on the Maxwell-Wagner model (Maxwell 1982 and Wagner 1913) for the inhomogeneous double layer dielectric structure. The dielectric structure was supposed to be composed of the fairly well-conducting ferrite grains. These are separated by the second thin layer of grain boundaries which are poorly conducting substances. These grain boundaries could be formed during the sintering process due to the superficial reduction or oxidation of crystallites in the porous materials as a result of their direct contact with the firing atmosphere (Reddy and Rao 1982). The grain boundaries of lower 
conductivity were found to be effective at lower frequencies while ferrite grains of high conductivity are effective at high frequencies (Koops 1951, Kumar and Srivastava 1994). This explains the higher values of $\varepsilon^{\prime}$ at lower frequencies and the decrease in $\varepsilon^{\prime}$ as the frequency increases.

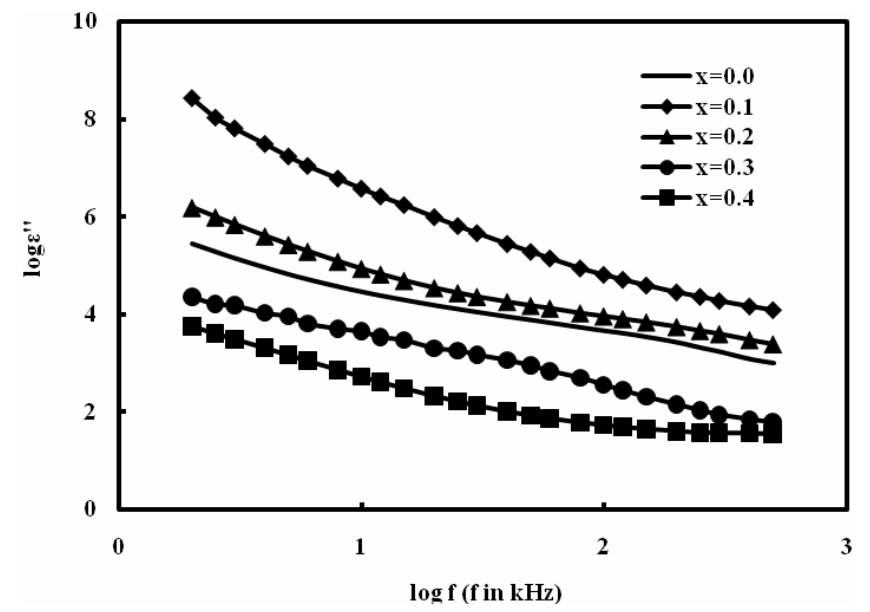

Fig. 4. Frequency dependent imaginary part of dielectric constant.

The real $\varepsilon^{\prime}$ and imaginary $\varepsilon^{\prime \prime}$ parts of the dielectric permittivity are given by the following Debye equation (Kingery et al. 1976) as

$$
\varepsilon^{\prime}=\varepsilon_{\infty}+\frac{\varepsilon_{0}-\varepsilon_{\infty}}{1+\omega^{2} \tau^{2}}
$$

where, $\tau$ is the relaxation time, $\epsilon_{0}$ the dielectric permittivity at a very low frequency and $\epsilon_{\infty}$ the dielectric permittivity at a very high frequency, respectively. This Debye equation indicates that $\epsilon^{\prime}$ decrease as the frequency increases. This is in agreement with the behaviour of $\epsilon^{\prime}$ in Figures 3 and 4 for the present studied samples.

Resistivity is an important electrical property for many applications. Resistivity was measured as a function of temperature for all the samples. The room temperature resistivity increases with $\mathrm{Zn}$ content. The dc resistivity decreases with temperature for all the samples. Resistivity vs. temperature graph is shown in Fig. 5. When the polycrystalline ferrites are considered, the resistivity arises from a contribution of the crystallite resistivity and the resistivity of the crystalline boundaries. The boundary resistivity is much greater than that of crystallite resistivity. So the boundaries have the greatest influence on the dc resistivity (Narayan et al. 1989). The increase of resistivity has been related to the increase of porosity at higher sintering temperatures since pores are non-conductive, which increases the resistivity of the material. The resistivity 
increases with increasing porosity because the charge carriers on their way face large number of pores i.e. obstacles.

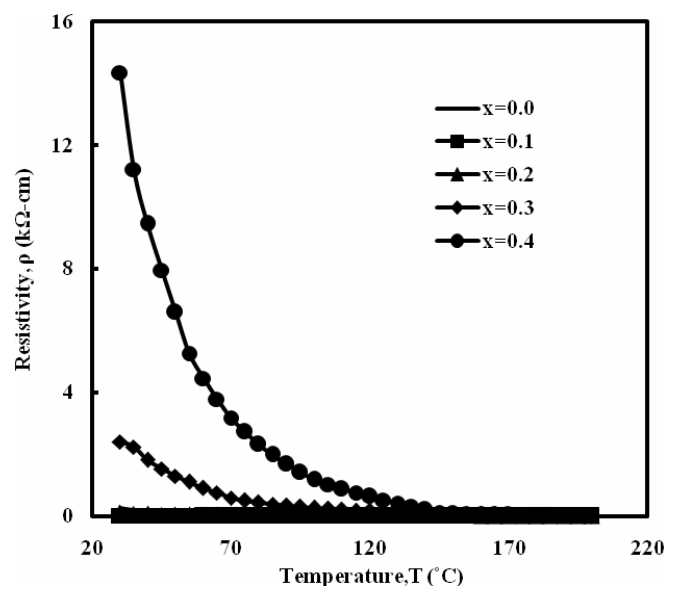

Fig. 5. Temperature dependent resistivity.

Fig. 6 shows the variation of dc resistivity with the increase in $\mathrm{Zn}$ concentration at room temperature. It is observed from Fig. 6 that resistivity increases markedly by the addition of $\mathrm{Zn}$ ion. The conduction mechanism in ferrite is considered as the electron hopping between $\mathrm{Fe}^{2+}$ and $\mathrm{Fe}^{3+}$ ions in the $\mathrm{B}$ sites. In the sample without $\mathrm{Zn}^{2+}$ content $(\mathrm{x}=0), \mathrm{Fe}$ concentration is maximum at the $\mathrm{B}$ sites, which is responsible for electrical

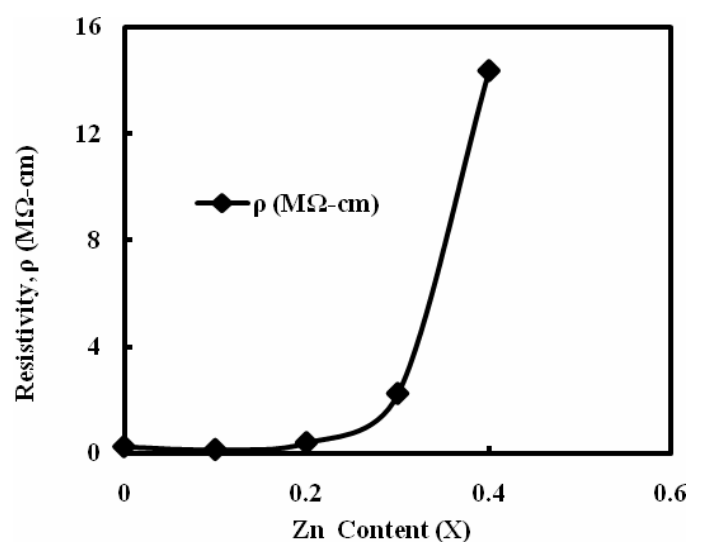

Fig. 6. Variation of resistivity with $\mathrm{Zn}$ content.

conduction in ferrites. An addition of $\mathrm{Zn}$ in the system reduces the concentration of $\mathrm{Fe}^{2+}$ ions due to the presence of $\mathrm{Zn}^{2+}$ ions at the $\mathrm{B}$ sites. Therefore, the observed increase in the dc resistivity with the increase in $\mathrm{ZnO}$ content may be attributed to the presence of decreased $\mathrm{Fe}^{2+}$ ions due to the incorporation of $\mathrm{ZnO}$. 


\section{CONCLUSION}

The XRD of all of the prepared samples showed the single phase inverse spinel structure without any detectable impurity. Lattice constant of the samples increases with increasing $\mathrm{Zn}^{2+}$ concentration which follows Vegard's law. The bulk density $\left(\rho_{\mathrm{B}}\right)$ is lower than the theoretical density $\left(\rho_{\mathrm{th}}\right)$. This may be due to the existence of pores which were formed and developed during the sample preparation or the sintering process. The theoretical densities of these samples remain almost constant whereas the bulk density decreases with $\mathrm{Zn}$ content up to $\mathrm{x}=0.2$. This might be caused by the limited content of $\mathrm{Zn}$ and may have generated intergranular pores. Again the bulk density increases with $\mathrm{Zn}$ content for $\mathrm{x}=0.3$ and for further addition with $\mathrm{x}=0.4$ it decreases which might be caused by the existence of slight amount of metal oxides such as $\mathrm{M}^{2+} \mathrm{O}\left(\mathrm{M}^{2+}: \mathrm{Fe}, \mathrm{Zn}\right)$. The porosity of the samples showed the opposite trend. The dielectric constant is found to decrease continuously with increasing frequency for all of the specimens exhibiting normal dielectric behavior of ferrites. The dielectric dispersion is rapid at lower frequency region and remains almost independent at the high frequency region. The incorporation of $\mathrm{Zn}$ into the $\mathrm{CoZn}_{\mathrm{x}} \mathrm{Fe}_{2-\mathrm{x}} \mathrm{O}_{4}$ has no pronounced effect on the dielectric constant at high frequency, but significantly decreases at the low frequency range. The dielectric behavior of ferrites may be explained on the basis of the mechanism of the dielectric polarization process and is similar to that of the conduction process. The $\mathrm{dc}$ resistivity decreases with temperature for all of the samples confirming the semiconducting behavior of the prepared ferrites. dc electrical resistivity increases markedly by the addition of $\mathrm{Zn}$ ion. The observed enhancement of dc resistivity with the increase in $\mathrm{ZnO}$ content may be attributed to the presence of decreased $\mathrm{Fe}^{2+}$ ions due to the incorporation of $\mathrm{ZnO}$. These investigation clearly point towards the merits of the $\mathrm{Zn}$ additive for preparing cobalt ferrites with improved properties for many applications.

\section{ACKNOWLEDGMENT}

The authors are grateful to the authorities of Materials Science Division, Atomic Energy Center, Dhaka (AECD), Bangladesh.

\section{REFERENCES}

Ahmed, M. A. and S. T. Bishay. 2003. Thermal studies of the electrical conductivity of LiCoYbferrites. J. Phys. Chem. Solids 64: 769-775.

Bammannavar, B. K., L. R. Naik, R. B. Pujar and B. K. Chougule. 2007. Preparation, characterization and physical properties of Mg-Zn ferrites. Indian J. Eng. Mater. Sci. 13: 381385.

Bellad, S. S. and B. K. Chougule. 2000. Composition and frequency dependent dielectric properties of Li-Mg-Ti ferrites. J. Mater. Chem. Phys. 66: 58-63.

Bellad, S. S., S. C. Watawe, A. M. Shaikh and B. K. Choughule. 2000. Cadmium substituted high permeability lithium ferrite. Bull. Mater. Sci. 23(2): 83-85. 
Bharati, K. K. and C. V. Ramana. 2011. Improved dielectric properties of La doped cobalt ferrite, J. Mater. Res. 26: 584-591.

Bhowmik, R. N. and N. Naresh. 2010. Structure, ac conductivity and complex impedance study of $\mathrm{Co}_{3} \mathrm{O}_{4}$ and $\mathrm{Fe}_{3} \mathrm{O}_{4}$ mixed spinel ferrites. Int. J. Eng. Sci. Tech. 2(8): 40-52.

Dean, J. A. 2005. Lange's Handbook of Chemistry. 16th ed., McGraw-Hill, New York.

Denton, A. R. and A. W. Ashcroft. 1991. Vegrad's law. J. Phys. Rev. A, 43: 4161-4164.

Gupta, N., S. C. Kashyap and D. C. Dube. 2007. Dielectric and Magnetic Properties of CitrateRoute Processed Li-Co Spinel Ferrites. J. Phys. Status. Solid 204: 2441-2452.

Iwauchi, K. 1971. Dielectric Properties of Fine Particles of $\mathrm{Fe}_{3} \mathrm{O}_{4}$ and Some Ferrites. Japan J. Appl. Phys. 10: 1520-1528.

Kim, K. J., H. K. Kim, Y. R. Park, G. Y. Ahn, C. S. Kim and J. Y. Park. 2006. Mössbauer and optical investigation of $\mathrm{Co}_{3-\mathrm{x}} \mathrm{Fe}_{\mathrm{x}} \mathrm{O}_{4}$ thin films grown by sol-gel process. J. Hyperfine Interactions 169:1363-1369.

Kingery, W. D., H. K. Bowen and D. R. Uhlman. 1976. Introduction to Ceramics. 2nd ed. New York.

Kolekar, C. B., P. N. Kamble, S. G. Kulkarni and A. S. Vaingankar. 1995. Effect of $\mathrm{Gd}^{3+}$ substitution on dielectric behaviour of copper cadmium ferrites. J. Mater. Sci. 30: 5784-5788.

Koops, C. 1951. J. Phys. Rev. 83: 121-124.

Kumar, B. and G. Srivastava. 1994. Dispersion observed in electrical properties of titanium substituted lithium ferrites. J. Appl. Phys. 75: 6115-6127.

Kumar, L. and M. Kar. 2012. Effect of $\mathrm{La}^{3+}$ substitution on the structural and magnetocrystalline anisotropy of nanocrystalline cobalt ferrite $\left(\mathrm{CoFe}_{2-\mathrm{x}} \mathrm{La}_{\mathrm{x}} \mathrm{O}_{4}\right)$. J. Cer. Int. 38: 4771-4782.

Maria, K. H., S. Choudhury and M. A. Hakim. 2010. Complex permeability and transport properties of Zn substituted Cu ferrites. J. Bang. Acad. Sci. 34(1): 1-18.

Maxwell, J.C. 1982. A Treatise on Electricity and Magnetism. Clarendon Press, Oxford.

Nalla Somaiah, Tanjore V. Jayaraman, P. A. Joy and Dibakar Das. 2012. Magnetic and magnetoelastic properties of $\mathrm{Zn}$-doped cobalt ferrites-CoFe $\mathrm{Ce}_{2 \mathrm{x}} \mathrm{Zn}_{\mathrm{x}} \mathrm{O}_{4}(\mathrm{x}=0.0,0.1,0.2$ and 0.3). J. Magn. Magn. Mater. 324: 2286-2291.

Narayan, R., R. B. Tripati, K. Das. 1989. Proc. of $5^{\text {th }}$ Int. Conf. on Ferrite. New Delhi, 267-273.

Nelson, J. B. and D. P. Riley. 1945. An experimental investigation of extrapolation methods in the derivation of accurate unit-cell dimensions of crystals. Proc. Phys. Soc. London 57: 160.

Reddy, P. and T. Rao. 1982. Dielectric behaviour of mixed Li-Ni ferrites at low frequencies. $J$. Less-Common Met. 86: 255-261.

Sattar, A. A., H. M. El-Sayed, K. M. El-shookrofy and M. M. El-Tabey. 2005. Improvement of the Magnetic Properties of Mn-Ni-Zn Ferrite by the Non-magnetic $\mathrm{Al}^{3+}$-Ion Substitution. J. Appl. Sci. 5(1): 162-168.

Singhal, S., T. Namgyal, S. Bansal and K. Chandra. 2012. Effects of Zn substitution on the magnetic properties of cobalt ferrite Nano particles prepared via sol-gel route. $J$. Electromagnetic Analysis and Applications 2: 376-381.

Wagner, K. 1913. J. Ann. Phys. 40: 817.

Xiwei, Qi, J. Zhou, Z. Yue, Z. Gui, L. Li. 2002. Effect of Mn substitution on the magnetic properties of MgCuZn ferrites. J. Magn. Magn. Mater. 251: 316-322.

Zhenxing, Y., J. Zhou, L. Li, Z. Gui. 2001. Effect of $\mathrm{MnO}_{2}$ on the electromagnetic properties of $\mathrm{NiCuZn}$ ferrites prepared by sol-gel auto-combustion. J. Magn. Magn. Mater. 233: 224-229.

Zhenxing, Y., J. Zhou, Z. Gui, L. Li. 2003. Magnetic and electrical properties of low-temperature sintered Mn-doped NiCuZn ferrites. J. Magn. Magn. Mater. 264: 258-263. 